\title{
Spontaneous intramedullary spinal cord haemorrhage due to anticoagulation therapy
}

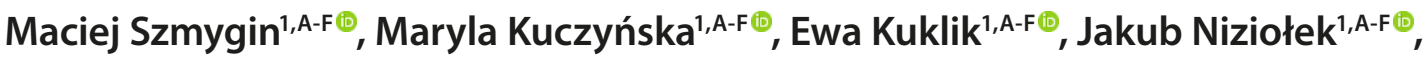 \\ Aleksandra Porzucek ${ }^{1, A-F}$, Anna Drelich-Zbroja ${ }^{1, A-F} \oplus$ \\ 'Medical University, Lublin, Poland \\ A - Research concept and design, B - Collection and/or assembly of data, C - Data analysis and interpretation, \\ $D$ - Writing the article, $E$ - Critical revision of the article, $F$ - Final approval of article
}

\begin{abstract}
Szmygin M, Kuczyńska M, Kuklik E, Niziołek J, Porzucek A, Drelich-Zbroja A. Spontaneous intramedullary spinal cord haemorrhage due to anticoagulation therapy. J Pre-Clin Clin Res. 2019; 13(4): 179-180. DOI: 10.26444/jpccr/115764
\end{abstract}

\begin{abstract}
Background: Anticoagulants are used mainly in the prevention of venous thromboembolism. The frequency of haemorrhagic complications is correlated with patients' age and level of International Normalized Ratio (INR). Spontaneous intramedullary spinal cord haemorrhage due to anticoagulation therapy is an extremely rare occurrence. A 62-year old male was admitted to hospital with acute abdominal pain and paraplegia. Because of persistent atrial fibrillation and previous history of ischaemic stroke, on admission the patient was treated with anticoagulant, INR - 15. MRI revealed an abnormal fusiform hyperintesity area in the spinal cord. 'Haemo' sequence confirmed the presence of hemosiderin deposits at the level of Th5 - Th7. Anticoagulation therapy might be a cause of spontaneous intramedullary spinal cord haemorrhage. Maintaining high levels of clinical suspicion and utilizing MRI with additional 'haemo' option may help in making the right diagnosis.
\end{abstract}

\section{Key words}

spontaneous, spinal cord, MR Imaging, intramedullary

\section{BACKGROUND}

Anticoagulants are used mainly in the prevention of venous thromboembolism. They can counteract such major complications as pulmonary embolism, heart infarction or ischaemic stroke. The unwanted effects of anticoagulation therapy include haemorrhages [1]. The frequency of haemorrhagic complications is correlated with patients' age and level of International Normalized Ratio (INR) [2]. However, spontaneous intramedullary spinal cord haemorrhage due to anticoagulation therapy is an extremely rare occurrence [3].

\section{CASE REPORT}

A 62-year-old male was admitted to hospital with acute abdominal pain, sweating and paraplegia. The patient reported persistent atrial fibrillation treated with anticoagulants (Warfarin), and a previous history of ischaemic stroke which caused mixed dysphasia.

On presentation, he was haemodynamically stable with significant changes in blood count. However, further lab tests revealed elevated INR -15 . Neurological examination showed complete sensory loss below Th6/Th7, muscle atonia and lack of deep reflexes in lower extremities and bilateral Babiński sign. CT examination disclosed no pathological changes in the spinal cord area.

Due to suspicion of spinal cord lesion, MRI was performed using a 1.5 Avanto Siemens Scanner. T2-weighted sequence disclosed intraspinal oedema from Th4 - Th8/Th9 (Fig. 1a, 1b). Further sequences showed an abnormal fusiform

Address for correspondence: Maciej Szmygin, Medical University, Lublin, Poland E-mail: mszmygin@gmail.com

Received:24.10.2019; accepted: 23.12.2019; first published: 31.12.2019
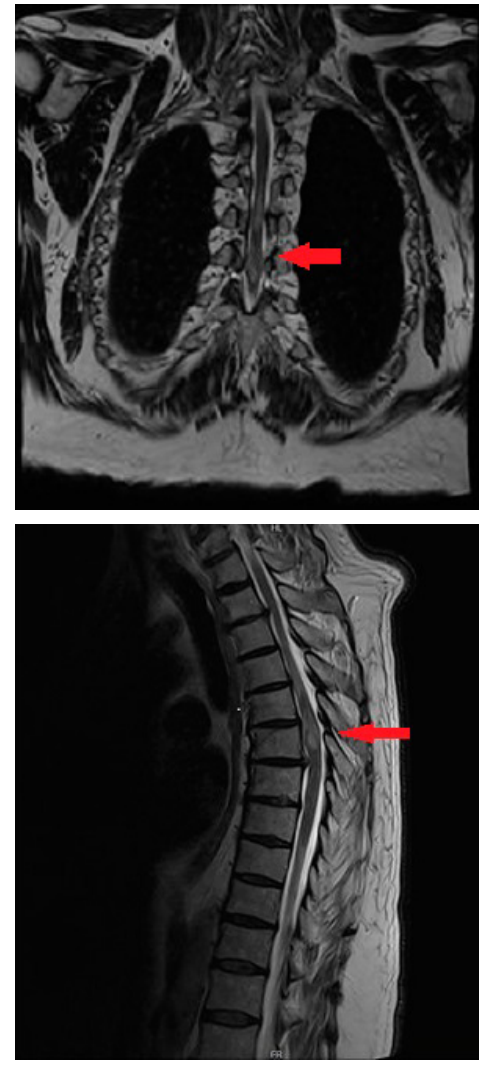

Figure 1a 1b. T2-weighted sequence showed intraspinal edema from Th4 to Th8/Th9, coronal and saggital projections

hyperintesity area in the spinal cord about $2 \mathrm{~cm} \times 1 \mathrm{~cm} \times 1 \mathrm{~cm}$ at the level of Th 5 and Th6. 'Haemo' sequence confirmed the presence of haemosiderin deposits at the level of Th $5-\mathrm{Th} 7$ (Fig. 1c). 


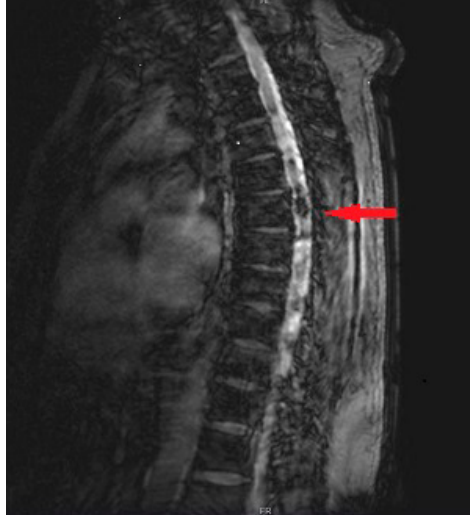

Figure 1c. Hemosiderin deposits at the leve of Th5 to Th7. "Hemo" sequence.

The on-call neurosurgeon disqualified the patient from surgical treatment and ordered anti-haemorrhagic and antioedemic medication. The warfarin therapy was discontinued and fresh frozen plasma and vitamin $\mathrm{K}$ were administered. Unfortunately, the clinical condition of the patients remained unchanged and he was further discharged to a rehabilitation facility.

\section{DISCUSSION}

Haematomyelia is a rare neurological disorder, most commonly caused by spinal cord trauma [4]. However, authors report non-traumatic causes of intramedullary spinal cord haemorrhage, such as vascular malformations, tumours or coagulation disorders [5]. Zeidmann and Olivi [6] described a case of an 81-year-old patient with spontaneus cervical intramedullary haemorrhage resulting from anticoagulation therapy. Similar to the presented case, the medication included Warfarin prescribed due to chronic atrial fibrillation. Uncontrolled intake led to elevated prothrombine times and acute bleeding.

Patients with haematomyelia suffer from acute sensory deficit and motor weakness caused by spinal cord compression. Laboratory tests often remain within normal limits, and no significant changes in blood count values are noted [7]. However, due to severe clinical manifestation and the deteriorating condition of the patient, MRI was performed. Imaging results showing a high signal in T1weighted sequence and low signal in T2-weighted sequence suggest a haemorrhaging process. Additional sequence enabling haemosiderin deposition detection, which in the above-mentioned Avanto Siemens MRI Scanner is called the 'haemo' sequence, confirmed the diagnosis of intramedullary haemorrhage. Lesions are most frequently found in the thoracic region, as described in this case report [8].

The treatment of intramedullary spinal cord haemorrhage remains controversial. Several authors compare surgical treatment and conservative treatment, with most of them recommending the first option [9]. However, according to Kharkar et al. [10], the late outcome results of patients who underwent the operation are comparable with those treated conservatively.

Oh et al. [11] suggests that early rehabilitation and physical therapy is an effective and important factor in improving function in patients with spontaneus intramedullary spinal cord haemorrhage.

In conclusion, non-traumatic, spontaneus haematomyelia caused by anticoagulation therapy is a rare occurrence and requires high levels of clinical suspicion and an MRI in order to make the right diagnosis. This case report pays attention to the crucial problem of INR monitoring during warfarin treatment.

\section{REFERENCES}

1. Alquwaizani M, Buckley L, Adams C, Fanikos J. Anticoagulants: A Review of the Pharmacology, Dosing, and Complications. Curr Emerg Hosp Med Rep. 2013;1(2):83-97. Published 2013 Apr 21.

2. Navgren M, Forsblad J, Wieloch M. Bleeding complications related to warfarin treatment: a descriptive register study from the anticoagulation clinic at Helsingborg Hospital. J Thrombosis Thrombolysis. 2013; 38(1): 98-104.

3. Brandt M. Spontaneous intramedullary haematoma as a complication of anticoagulant therapy. Acta Neurochir (Wien) 1980; 52: 73-77.

4. Leep Hunderfund AN, Wijdicks EFM. Intramedullary spinal cord hemorrhage (hematomyelia). Rev Neurol Dis. 2009;6:E54-61.

5. Karavelis A, Foroglou G, Petsanas A, et al. Spinal cord dysfunction caused by non-traumatic hematomyelia. Spinal Cord. 1996; 34: 268-71.

6.Zeidman SM, Olivi A. Cervical intramedullary hemorrhage as a result of anticoagulant therapy. J Spinal Disord. 1993; 6: 456-7.

7. Famularo G, Sajeva MR, Gasbarrone L. Warfarin-associated Hematomyelia. Int Med. 2014; 53(6): 623-626. doi:10.2169/ internalmedicine.53.1544

8. Lu DC, Lawton MT. Clinical presentation and surgical management of intramedullary spinal cord cavernous malformations. Neurosurg Focus. 2010; 29: E12.

9. Chao C-H, Tsai T-H, Huang T-Y, et al. Idiopathic spontaneous intraspinal intramedullary hemorrhage: a report of two cases and literature review. Clin Neurol Neurosurg. 2013; 115: 1134-6.

10. Kharkar S, Shuck J, Conway J, et al. The natural history of conservatively managed symptomatic intramedullary spinal cord cavernomas. Neurosurgery 2007; 60: 865-72.

11. Oh HM, Nam TW, Kim JH, Jung TD. Effects of rehabilitation on spontaneous intramedullary spinal cord hemorrhage (hematomyelia) patient without surgery A case report. Medicine (Baltimore). 2018 Nov; 97(48): e13414. 